OPEN ACCESS

Edited by: Jun Wang,

University of Wisconsin-Madison, United States

Reviewed by: Hussein Togun,

Thi Qar University, Iraq

Zhiwei Zhou,

Tsinghua University, China

*Correspondence:

Cenxi Yuan

yuancx@mail.sysu.edu.cn

Specialty section: This article was submitted to Nuclear Energy,

a section of the journal

Frontiers in Energy Research

Received: 09 March 2021 Accepted: 02 June 2021 Published: 21 June 2021

Citation:

Cai B, Chen S, Wu T, Wang $Y$, Zhang Z, Yuan $C$, Zhang $C$ and $G e Y$ (2021) Neutronic Design for Heat Pipe Reactor With Annular and Accident

Tolerant Fuels.

Front. Energy Res. 9:678262. doi: 10.3389/fenrg.2021.678262

\section{Neutronic Design for Heat Pipe Reactor With Annular and Accident Tolerant Fuels}

\author{
Boshuai Cai, Shengli Chen, Tianfan Wu, Yujing Wang, Zhaozhan Zhang, Cenxi Yuan*, \\ Chunyu Zhang and Yulin Ge
}

Sino-French Institute of Nuclear Engineering and Technology, Sun Yat-sen University, Zhuhai, China

Several core designs of heat pipe reactors with megawatt power were proposed for extreme environments, such as the deep space, the deep sea, and the earthquake locations. However, the existing designs have either the difficulty of manufacture or potential issues of transport. In the present work, a heat pipe design is proposed with an annular fuel element to replace the cylindrical and hexagon fuel elements. In addition, candidate accident tolerant fuels, such as the $\mathrm{UN}$ and $\mathrm{U}_{3} \mathrm{Si}_{2}$ fuels, are implemented. The neutronic properties of the new reactor design are systematically investigated by the OpenMC Monte Carlo code simulations. It is found that $\mathrm{BeO}$ presents a better effect of reducing the axial power deviation than $\mathrm{Al}_{2} \mathrm{O}_{3}$. The criticality of the proposed design is verified by two configurations of control drums. The depletion calculations show that each design can operate for decades of years.

Keywords: heat pipe reactor, accident tolerant fuel, annular fuel, neutronic study, U3Si2 fuel

\section{INTRODUCTION}

The heat pipe reactor is a type of micro nuclear reactor generating electricity by the evaporation and liquefaction of the metalworking fluid in the heat pipes to remove the fission heat from the reactor core. Its appearance was to meet the demand for electric power supporting the space exploration mission. In 1996, two fission power systems, the Heatpipe Power System (HPS) and the Heatpipe Bimodal System (HBS), were reported by Houts et al. (Houts et al., 1996a; Houts et al., 1996b) for use at lunar and planetary bases. As a derivative of the HPS design, the Heatpipe-Operated Mars Exploration Reactor (HOMER) was proposed with $20 \mathrm{kWe}$ for exploitation on the surface of Mars (Poston, 2001). Later, a $100 \mathrm{kWe}$ Martian/Lunar surface reactor system is designed to support manned extraterrestrial exploration (Bushman et al., 2004). Three concepts of the Scalable AMTEC Integrated Reactor Space Power System (SAIRS) with high power $(111 \mathrm{kWe})$ were developed by ElGenk and Tournier (El-Genk and Tournier, 2004). They also proposed a $110 \mathrm{kWe}$ Heat PipesSegmented Thermoelectric Module Converters (HP-STMCs) Space Reactor Power system (SRPS) and demonstrated its performance (El-Genk and Tournier, 2004a; El-Genk and Tournier, 2004b). The compact structure of the heat pipe reactor makes it suitable to be applied in a moving condition (Yan et al., 2020). This also attracts applications in remote areas far from a reliable electrical grid, e.g., the exploration of deep sea, the relief for earthquake locations, etc. (Mcclure et al., 2015; Levinsky et al., 2018).

As limited by the early space mission, the electric power of conventional heat pipe reactor was usually low and far below megawatt (MW) (Levinsky et al., 2018; Yan et al., 2020). The HPS, HBS, and HOMER were all designed below $100 \mathrm{kWe}$ (Houts et al., 1996a; Houts et al., 1996b; Poston, 2001). The designed power of several heat pipe reactors were proposed to around $100 \mathrm{kWe}$ to meet 
the demand of the increased mission time and increased distance between the target planet and the earth, e.g., the one designed for the Martian/Lunar surface exploration (Bushman et al., 2004), the SAIRS (El-Genk and Tournier, 2004), and the HP-STMCs (ElGenk and Tournier, 2004a; El-Genk and Tournier, 2004b). For remote installations, the power is identified by the U.S. Department of Energy (DOE) and Department of Defense (DOD) to be between 1 and 10 MWe (Sterbentz et al., 2017a). Most heat pipe reactors are designed to be at kilowatt $(\mathrm{kW})$ level, and only three types of heat pipe reactor core are designed to be at MW level. The first one is the monolith type proposed by Los Alamos National Laboratory (LANL) (Mcclure et al., 2015). The other two, i.e., the fuel element type requiring new hexagonally shaped annular fuel pellet and the liquid metal pool type immersing the fuel pins and the heat pipes in a tank of liquid metal, are both proposed by the Idaho National Laboratory (INL) (Sterbentz et al., 2017a) to avoid using the stainless steel monolithic core evaluating the LANL design (Sterbentz et al., 2017b).

Even though these two types avoid the difficulty of drilling holes in the monolith block, the fuel element type still needs the development of a new hexagonally shaped annular fuel pellet (Sterbentz et al., 2017a). In addition, there are potential issues when transporting liquid metal for the liquid metal pool type (Sterbentz et al., 2017a). A new type of heat pipe reactor is yet to be designed and studied. Inspired by the hexagonal array of six fuel pins and a heat pipe, the authors propose the combination of the monolith type and the cylindrical annular fuel element. This reduces the difficulty of manufacture by reducing the number of holes that have to be drilled and increasing the radius of hole.

Since the Fukushima disaster happened in 2011, the Accident Tolerant Fuel (ATF) attracts the attention of researchers. Fuels with higher thermal conductivity and/or higher uranium density are important candidates of ATF (Chen et al., 2020a). The UN fuel and the incorporation of $\mathrm{Mo}$ into $\mathrm{UO}_{2}$ (U-Mo) fuel are two types of ATFs whose thermal conductivity is higher than that of $\mathrm{UO}_{2}$, and more interestingly, increases with increasing temperature (Ross et al., 1988; Burkes et al., 2015; Chen et al., 2020a). These two types of ATF have been applied to the heat pipe reactor (Poston, 2001; El-Genk and Tournier, 2004b; Bushman et al., 2004; El-Genk and Tournier, 2004; Mcclure et al., 2015; Yan et al., 2020). But the $\mathrm{U}_{3} \mathrm{Si}_{2}$ fuel, which has good performance under irradiation, high melting point $\left(1665^{\circ} \mathrm{C}\right.$ ) (Hofman, 1986 ; Brown et al., 2015; Chen et al., 2020a), and the same advantage of thermal conductivity as UN and U-Mo (White et al., 2015; Chen et al., 2020a), is yet to be studied. A recent study of the thermalmechanical behaviors found that $\mathrm{UN}$ and $\mathrm{U}_{3} \mathrm{Si}_{2}$ have a flatter distribution of temperature than $\mathrm{UO}_{2}$ (Zeng et al., 2021). In recent years, the neutronic performance of $\mathrm{U}_{3} \mathrm{Si}_{2}$ fuel was investigated with FeCrAl cladding. The high thermal conductivity and the high uranium density of $\mathrm{U}_{3} \mathrm{Si}_{2}$ compensate for the suppression of reactivity caused by the large thermal neutron absorption cross section of $\mathrm{FeCrAl}$ (Chen and Yuan, 2017). The analytical formula describing the radial properties of $\mathrm{U}_{3} \mathrm{Si}_{2}$ fuel pins and annular $\mathrm{U}_{3} \mathrm{Si}_{2}$ fuel with FeCrAl cladding was proposed (Chen et al., 2019; Chen et al., $2020 \mathrm{~b})$. The transmutation of the minor actinides in $\mathrm{U}_{3} \mathrm{Si}_{2^{-}}$

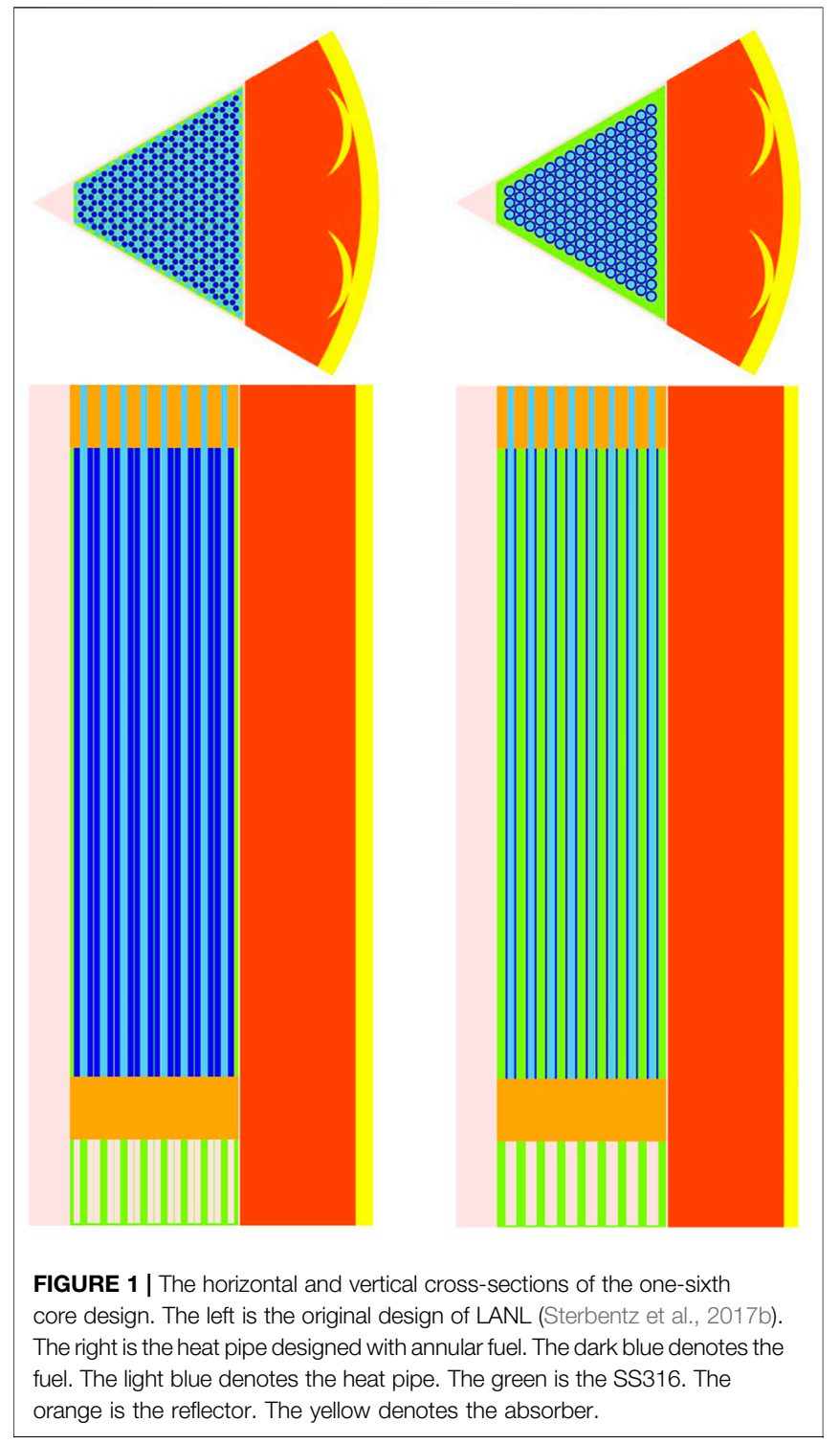

FeCrAl and $\mathrm{U}_{3} \mathrm{Si}_{2}$-SiC was proposed and investigated by the Monte Carlo simulations (Chen and Yuan, 2019). Therefore, the $\mathrm{U}_{3} \mathrm{Si}_{2}$ fuel is implemented for neutronic investigation in this work.

In this paper, a new type of reactor that combines the monolith type and the fuel element type is proposed. The new design adopts a cylindrical annular fuel element in a monolith. This decreases the radial power gradient of the fuel pin shown in Ref. (Sterbentz et al., 2017b). The ordinary $\mathrm{UO}_{2}$ fuel and two ATFs, $\mathrm{UN}$ and $\mathrm{U}_{3} \mathrm{Si}_{2}$, are implemented. The details of the original LANL design, the modification and the Monte Carlo code used are presented in Section Model and calculation. The results and the discussion on the neutronic behavior of the proposed reactor are presented in Section Result and Discussion. Finally, a summary and an outlook are given in Section Summary and Outlook. 
TABLE 1 | Geometric parameters of the LANL design (Sterbentz et al., 2017b).

\begin{tabular}{ll} 
& Radial absorber \\
\hline Material & $\mathrm{B}_{4} \mathrm{C}$ \\
Density & $2.51 \mathrm{~g} / \mathrm{cm}^{3}$ \\
B-10 enrichment & $90 \%$ \\
Inner radius & $77.85 \mathrm{~cm}$ \\
Thickness & $4.17 \mathrm{~cm}$ \\
Length & $201 \mathrm{~cm}$ \\
\hline
\end{tabular}

\section{Control drum}

\begin{tabular}{ll}
\hline Number & 12 \\
\hline & \multicolumn{1}{c}{ Absorber part } \\
\hline Material & $\mathrm{B}_{4} \mathrm{C}$ \\
Density & $2.51 \mathrm{~g} / \mathrm{cm}^{3}$ \\
B-10 enrichment & $90 \%$ \\
Shape & Crescent-shape \\
Length & $200 \mathrm{~cm}$
\end{tabular}

\begin{tabular}{ll}
\hline & Reflector part \\
\hline Material & $\mathrm{Al}_{2} \mathrm{O}_{3}$ \\
Density & $3.9 \mathrm{~g} / \mathrm{cm}^{3}$ \\
Outer radius & $12.5 \mathrm{~cm}$ \\
Length & $200 \mathrm{~cm}$
\end{tabular}

\begin{tabular}{ll}
\hline & Radial reflector \\
\hline Material & $\mathrm{Al}_{2} \mathrm{O}_{3}$ \\
Density & $3.9 \mathrm{~g} / \mathrm{cm}^{3}$ \\
Shape & Hexagonal hollow cylinder \\
Outer radius & $77.85 \mathrm{~cm}$ \\
Length & $200.5 \mathrm{~cm}$ \\
Thickness & $\sim 21-29 \mathrm{~cm}$
\end{tabular}

\section{Monoliths}

\begin{tabular}{ll} 
Number & 6 \\
\hline & \multicolumn{1}{c}{ Fuel pins } \\
\hline Number & $3522^{*} 6$ \\
Material & $\mathrm{UO}_{2}$ \\
Density & $10.96 \mathrm{~g} / \mathrm{cm}^{3}$ \\
Porosity & $4 \%$ \\
U-235 enrichment & $19.75 \%$ \\
Diameter & $1.412 \mathrm{~cm}$ \\
Length & $150 \mathrm{~cm}$ \\
Gas gap material & $\mathrm{H}_{2}$ \\
Gas gap thickness & $0.0065 \mathrm{~cm}$ \\
Fuel pin to fuel pin pitch & $1.60 \mathrm{~cm}$ \\
& \multicolumn{1}{c}{$\mathbf{H e a t}$ pipes } \\
\hline & 204 \\
\hline Number & $\mathrm{K}$ \\
Material & $100 \mathrm{~g}$ \\
Mass per heat pipe & $1.575 \mathrm{~cm}$ \\
Diameter & $165 \mathrm{~cm}$ \\
Length in core & $1.60 \mathrm{~cm}$ \\
Heat pipe to heat pipe pitch & $1.60 \mathrm{~cm}$ \\
Heat pipe to fuel pin pitch &
\end{tabular}

\begin{tabular}{ll}
\hline & Stainless steel part \\
\hline Material & $\mathrm{SS} 316$ \\
Density & $8.03 \mathrm{~g} / \mathrm{cm}^{3}$ \\
Composition & $68 \% \mathrm{Fe}, 14 \% \mathrm{Ni}$, and $18 \% \mathrm{Cr}$ \\
&
\end{tabular}

TABLE 1 | (Continued) Geometric parameters of the LANL design (Sterbentz et al., 2017b).

\begin{tabular}{|c|c|}
\hline \multicolumn{2}{|r|}{ Radial absorber } \\
\hline Heat pipe to edge & $0.15 \mathrm{~cm}$ \\
\hline Horizontal shape & Isosceles trapezoid with base angle of $60^{\circ}$ \\
\hline Trapezoid height & $40.275 \mathrm{~cm}$ \\
\hline Trapezoid upper base & $9.67 \mathrm{~cm}$ \\
\hline \multicolumn{2}{|r|}{ Top reflector } \\
\hline Material & $\mathrm{BeO}$ \\
\hline Density & $3.01 \mathrm{~g} / \mathrm{cm}^{3}$ \\
\hline Shape & Quadrilateral \\
\hline Horizontal shape & Isosceles trapezoid with base angle of $60^{\circ}$ \\
\hline Length & $15 \mathrm{~cm}$ \\
\hline Holes number & 204 \\
\hline \multicolumn{2}{|r|}{ Bottom reflector } \\
\hline Material & $\mathrm{BeO}$ \\
\hline Density & $3.01 \mathrm{~g} / \mathrm{cm}^{3}$ \\
\hline Shape & Quadrilateral \\
\hline Horizontal shape & Isosceles trapezoid with base angle of $60^{\circ}$ \\
\hline Length & $15 \mathrm{~cm}$ \\
\hline \multicolumn{2}{|r|}{ Gas plenum part } \\
\hline Material & SS316 \\
\hline Density & $8.03 \mathrm{~g} / \mathrm{cm}^{3}$ \\
\hline Holes numbers & 352 \\
\hline Shape & Same shape as bottom reflector \\
\hline Height & $20 \mathrm{~cm}$ \\
\hline \multicolumn{2}{|r|}{ Bottom plate } \\
\hline Material & SS316 \\
\hline Density & $8.03 \mathrm{~g} / \mathrm{cm}^{3}$ \\
\hline Height & $0.5 \mathrm{~cm}$ \\
\hline
\end{tabular}

Cylindrical emergency control rod

$\begin{array}{ll}\text { Material } & \mathrm{B}_{4} \mathrm{C} \\ \text { Density } & 2.51 \mathrm{~g} / \mathrm{cm}^{3} \\ \text { B-10 enrichment } & 90 \% \\ \text { Radius } & 5.6 \mathrm{~cm} \\ \text { Height } & 200 \mathrm{~cm}\end{array}$

\begin{tabular}{lc}
\hline & Annular emergency control rod \\
\hline Material & $\mathrm{B}_{4} \mathrm{C}$ \\
Density & $2.51 \mathrm{~g} / \mathrm{cm}^{3}$ \\
B-10 enrichment & $90 \%$ \\
Inner radius & $6.85 \mathrm{~cm}$ \\
Outer radius & $8.85 \mathrm{~cm}$ \\
Height & $200 \mathrm{~cm}$
\end{tabular}

\section{MODEL AND CALCULATION}

\section{The LANL Design}

The megawatt heat pipe reactor investigated in this work was originally proposed by LANL in 2015, of which the designed power is $5 \mathrm{MWt}$ and the designed cycle length is 5 years (Mcclure et al., 2015). This reactor core consists mainly of six monoliths, twelve control drums, two emergency control rods (one is cylindrical, and another is annular), a radial reflector, and a radial absorber. The monolith is in shape of 


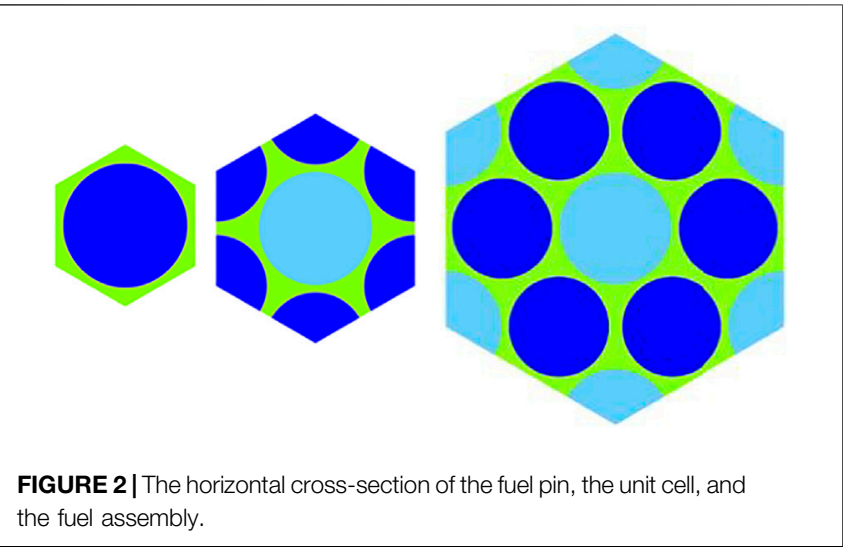

a quadrilateral with an isosceles trapezoid base. The base angle of the trapezoid is $60^{\circ}$. It is composed of 352 fuel pins, 204 heat pipes, two axial reflectors (one is on the top and another is on the bottom), a gas plenum part, and a stainless steel part where cylindrical holes are dug out along with the vertical direction to put the fuel pins and the heat pipes. The top reflector is also punched for crossing the heat pipes. The fuel pins and the heat pipes are arranged according to a hexagonal grid, as shown in the left panel of Figure 1. The center of the core is retained in order to insert the two emergency control rods to shut down the reactor suddenly.

In general, the reactivity is adjusted by the control drums surrounding the six monoliths and by the radial absorber. Each cylindrical control drum is composed of two parts. The first part is a crescent made of absorber material. The second is made of reflector materials. By rotating the control drum to let the absorber part be closer to the monolith, one can reduce the reactivity. On the bottom of the core, there is a cylindrical plate. The geometric parameters are extracted from the simulations made by INL (Sterbentz et al., 2017b). It should be mentioned that all published reports investigating this LANL monolith type design did not show the detailed geometry of control drums. The authors
TABLE 2 | Geometric Parameters of the annular fuel design.

\begin{tabular}{ll}
\hline Heat pipe diameter & $1.575 \mathrm{~cm}$ \\
Inner diameter of fuel & $1.775 \mathrm{~cm}$ \\
Outer diameter of fuel & $2.700 \mathrm{~cm}$
\end{tabular}

infer from Ref (Mcclure et al., 2015). that the absorber part (crescent-shape) is an intersection of two circles whose diameters are 25 and $33.3 \mathrm{~cm}$, and the centers are located at a distance of $12.5 \mathrm{~cm}$. As for the reflectors, INL used $\mathrm{BeO}$ (Sterbentz et al., 2017b) for the axial reflector that is filled with $\mathrm{Al}_{2} \mathrm{O}_{3}$ in the reports of LANL and ANL (Mcclure et al., 2015; Lee et al., 2019). The details of materials and the geometry are listed in Table 1 . The effects of different reflector materials are discussed in Section Axial Power Distribution.

In order to verify the calculation of OpenMC, the authors refer to the models used by Lee et al. (Lee et al., 2019). In their work, the $\mathrm{k}$ eigenvalue calculation is firstly made on three simple models: the fuel pin, the unit cell, and the fuel assembly, of which the horizontal cross sections are drawn in Figure 2. The fuel pin is only a cylindrical fuel surrounded by SS316. The unit cell consists of a heat pipe, six one-sixth fuel pins, and the rest region filled with SS316. The fuel assembly consists of six fuel pins, a heat pipe, six one-sixth heat pipes, and the rest region filled with SS316. Moreover, Lee et al. calculated four cases for the whole core. Each case was set with a specific angle of control drums (Lee et al., 2019). The two cases used in the present work are drawn in Figure 3.

\section{Proposed Modification}

The present work puts forward a modification that replaces the 352 cylindrical fuels and 204 heat pipes with 150 annular-fuelheat-pipe units. This not only decreases the number of holes that have to be dug out in the monolith, but also decreases the radial power gradient of the fuel pin. The right panel of Figure 1 depicts the horizontal cross section of this design. The geometric
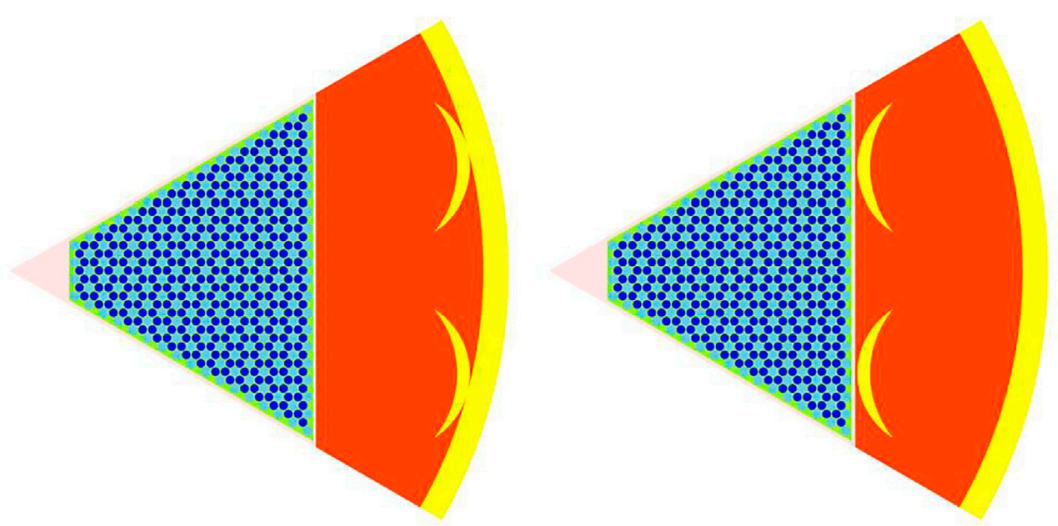

FIGURE 3 | The configuration of cases $A$ and D in Ref. (Lee et al., 2019). The angle of two control drums in each case are respectively $\left(0^{\circ}, 0^{\circ}\right)$, $\left(180^{\circ}\right.$, $\left.180^{\circ}\right)$. 
TABLE 3 | Key parameters of the three fuel materials.

\begin{tabular}{|c|c|c|c|c|}
\hline Fuel & T.D. $\left(\mathrm{g} / \mathrm{cm}^{3}\right)$ & U Enrichment (\%) & Wo\% of U & Porosity (\%) \\
\hline $\mathrm{UO}_{2}$ & 10.96 Sterbentz et al. (2017b) & 19.75 & 88.1 Chen et al. (2020a) & 4 Sterbentz et al. (2017b) \\
\hline UN & 14.32 Muta et al. (2008) & 19.75 & 94.4 Chen et al. (2020a) & 15 \\
\hline $\mathrm{U}_{3} \mathrm{Si}_{2}$ & 12.20 White et al. (2015) & 19.75 & 92.7 Chen et al. (2020a) & 4 White et al. (2015) \\
\hline
\end{tabular}

T.D. means the theoretical density

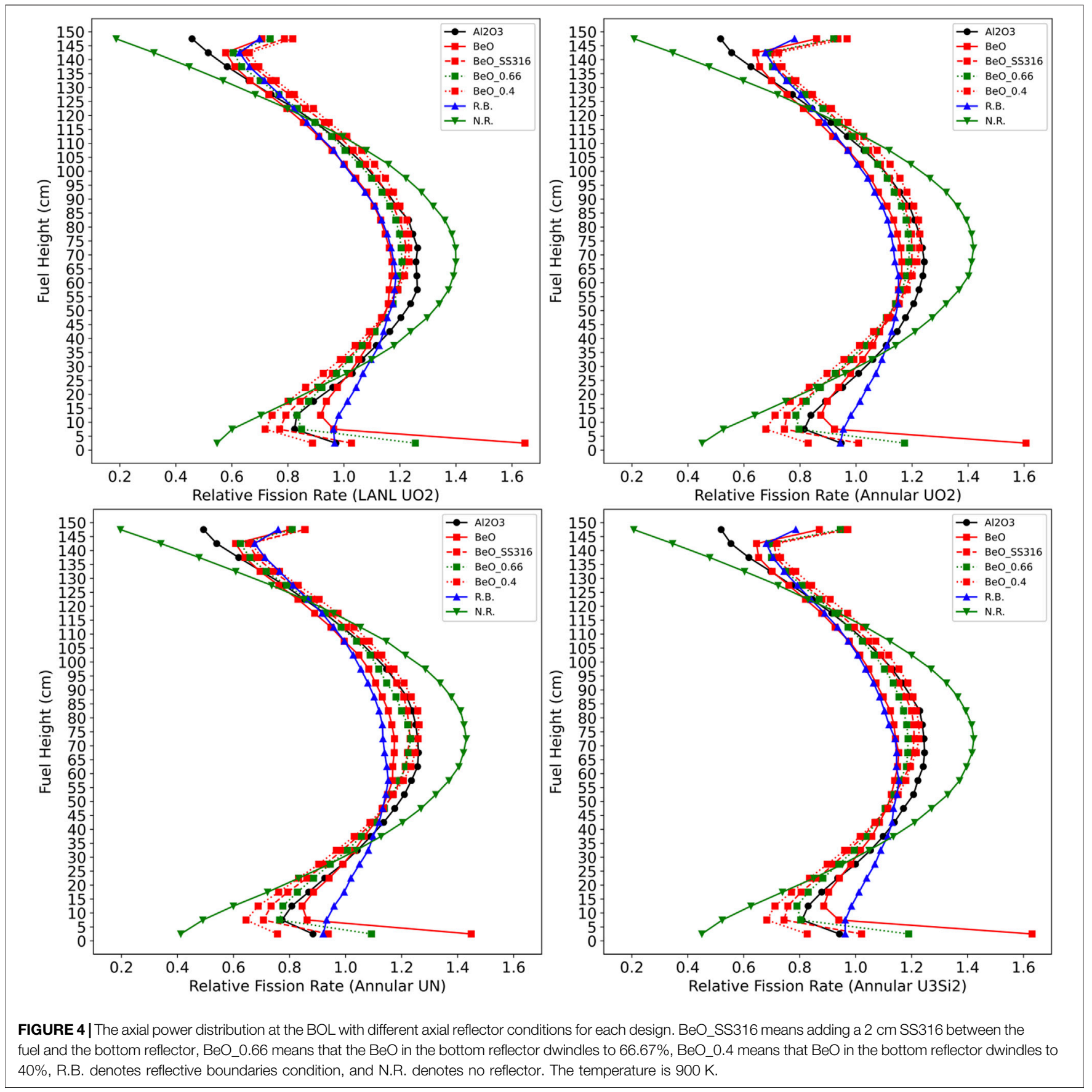


TABLE 4 | The standard deviation of relative fission rate for each axial reflector condition under $900 \mathrm{~K}$.

\begin{tabular}{|c|c|c|c|c|c|c|c|}
\hline Design & $\mathrm{Al}_{2} \mathrm{O}_{3}$ & $\mathrm{BeO}$ & BeO_SS316 & BeO_0.66 & BeO_0.4 & R.B. & N.R. \\
\hline LANL $\cup_{2}$ & 0.235 & 0.215 & 0.179 & 0.190 & 0.188 & 0.169 & 0.358 \\
\hline Annular $\cup_{2}$ & 0.215 & 0.194 & 0.167 & 0.163 & 0.183 & 0.144 & 0.368 \\
\hline Annular UN & 0.227 & 0.189 & 0.190 & 0.187 & 0.209 & 0.142 & 0.377 \\
\hline Annular $\mathrm{U}_{3} \mathrm{Si}_{2}$ & 0.218 & 0.192 & 0.168 & 0.162 & 0.182 & 0.144 & 0.368 \\
\hline
\end{tabular}

TABLE 5 $\mid k_{\text {eff }}$ of the LANL design and the annular fuel design for case A and case $\mathrm{D}$ under $900 \mathrm{~K}$

\begin{tabular}{lcc}
\hline & Case A & Case D \\
\hline $\mathrm{UO}_{2}$ & $1.05992(68)^{\mathrm{bc}}$ & $0.94803(58)^{\mathrm{bc}}$ \\
& $1.03344(67)^{\mathrm{bd}}$ & $0.92314(62)^{\mathrm{bd}}$ \\
$\mathrm{UN}$ & $1.09878(67)^{\mathrm{ad}}$ & $1.02433(63)^{\mathrm{ad}}$ \\
& $1.04662(61)^{\mathrm{bd}}$ & $0.96090(64)^{\mathrm{bd}}$ \\
$\mathrm{U}_{3} \mathrm{Si}_{2}$ & $1.07077(62)^{\mathrm{ad}}$ & $0.96866(58)^{\mathrm{ad}}$ \\
& $1.05647(64)^{\mathrm{bd}}$ & $0.94943(57)^{\mathrm{bd}}$
\end{tabular}

${ }^{a}$ Calculation with the theoretical density.

${ }^{b}$ Calculation with the theoretical density considering the porosity.

'Simulation for LANL design.

${ }^{d}$ Simulation for annular fuel design.

parameters of the annular design are listed in Table 2. The scale and number of holes are changed in the proposed monolith.

Besides the $\mathrm{UO}_{2}$ fuel employed in the LANL design, two ATFs are implemented for the annular fuel design. The parameters of these three fuels are listed in Table 3. Note that the porosity of fuel produced in the fabrication process is considered for defining the density of the fuel to transform the theoretical density to the real density. For UN, the fabrication methods result in different porosities ranging from 0 to $20 \%$, to which thermal conductivity is sensible (Ross et al., 1988; Hayes et al., 1990; Arai et al., 1992; Muta et al., 2008; Solntceva et al., 2016). In the present work, the porosity of $\mathrm{UN}$ is set to be $15 \%$ in order to reach the criticality. If the theoretical density of UN is directly used for calculation, the two extreme cases (of which $k_{\text {eff }}$ are given in Table 5) cannot reach the subcritical. It is thus impossible to reach the criticality by the rotation of the control drums. While the $15 \%$ porosity of $\mathrm{UN}$ is taken into account, the core is supercritical at case A and subcritical at case D.

\section{Monte Carlo Simulation}

The open-sourced Monte Carlo particle transport code OpenMC (Romano et al., 2015) is used for neutronic calculations. In the depletion calculation, a fourth-order commutator-free integrator, i.e., the CE/LI CFQ4 algorithm, is used. The nuclear data used in the present work is ENDF/B-VII.1.

\section{RESULTS AND DISCUSSION}

\section{Axial Power Distribution}

Along the vertical direction, the fuel region is divided into 30 segments to record the fission rate. The relative fission rate is calculated by $\frac{\text { fissionrate }(z)}{\overline{\text { fission rate }}}$, where $z$ is the axial location and fission rate means the average fission rate. The axial power distribution at the Beginning of Life (BOL) is calculated by OpenMC for the LANL design and the annular fuel element modification. The results are shown in Figure 4.

The axial power distribution of the LANL design, taking $\mathrm{Al}_{2} \mathrm{O}_{3}$ as the axial reflector, presents a similar shape and range shown in the LANL report (Mcclure et al., 2015). The power decreases from the middle to the two endpoints. Interestingly, it slightly increases at the bottom. Since the reflector reduces the leakage of neutrons, the inhomogeneity of axial power is reduced.

The effect on axial power distribution of $\mathrm{BeO}$ taken as the axial reflector by Sterbentz et al. (Sterbentz et al., 2017b) is also investigated. The $\mathrm{BeO}$ has a similar effect as the reflective boundary condition in the upper $3 / 4$, but a jump of power on the bottom. Two reasons may explain why the power on the bottom is higher than that on the top. On the one hand, it is asymmetric along the vertical direction, i.e., holes are dug out in the top reflector to let the heat pipes pass through while the bottom reflector is solid. Thus more reflectors are set on the bottom than the top. On the other hand, the neutrons are moderated while reflected by the $\mathrm{BeO}$. This increases the fission rate. Therefore, the power increases a lot comparing with the case of the reflective boundary condition.

When $\mathrm{BeO}$ is taken as the axial reflector, the jump of power also means that the reflection on the bottom is over the expectation or over that on the top. If one either increases the distance between the fuel and the bottom reflector or reduces the amount of $\mathrm{BeO}$ in the bottom reflector, the increasing power can be mediated. In fact, there are some small holes in the bottom reflector in order to let the fission gas pass through and enter the gas plenum under the reflector, which is not reported. If one sets the same amount of $\mathrm{BeO}$ on the bottom as the top, a well symmetric power distribution is obtained, as shown by the red dotted line in Figure 4.

The phenomenons discussed above also appear for the annular fuel element modifications. When $\mathrm{UO}_{2}$ is implemented, the standard deviation of the relative fission rate for the modification is lower than that of the LANL design only except for the N.R. condition. Thus, the modification reduces the axial power deviation. Since the green dotted line shows the lowest standard deviation of relative fission rate except for the R.B. condition shown in Table 4, the $\mathrm{BeO}$ in the bottom reflector is reduced to $66.67 \%$ in the following studies.

\section{Effective $k$ Eigenvalue $\left(\mathrm{K}_{\text {eff }}\right)$ and Depletion Calculation}

We use OpenMC to calculate the $k_{\text {eff }}$ for the cases shown in Figures 2, 3. The $\mathrm{k}_{\text {eff }}$ results are listed in Table 5 and Table 6. As 
TABLE 6 | The effect of Mo in SS316 on $\mathrm{k}_{\text {eff }}$ for the three simple models under $293.6 \mathrm{~K}$

\begin{tabular}{|c|c|c|c|c|}
\hline Percentage of Mo & $0 \%$ & $1 \%$ & $2 \%$ & $3 \%$ \\
\hline Fuel pin & $1.41767(55)$ & $1.41612(60)$ & $1.41456(54)$ & $1.41309(57)$ \\
\hline Unit cell & $1.39996(56)$ & $1.39816(57)$ & $1.39535(55)$ & $1.39373(61)$ \\
\hline Fuel assembly & $1.40018(58)$ & $1.39830(58)$ & $1.39596(61)$ & $1.39417(55)$ \\
\hline
\end{tabular}

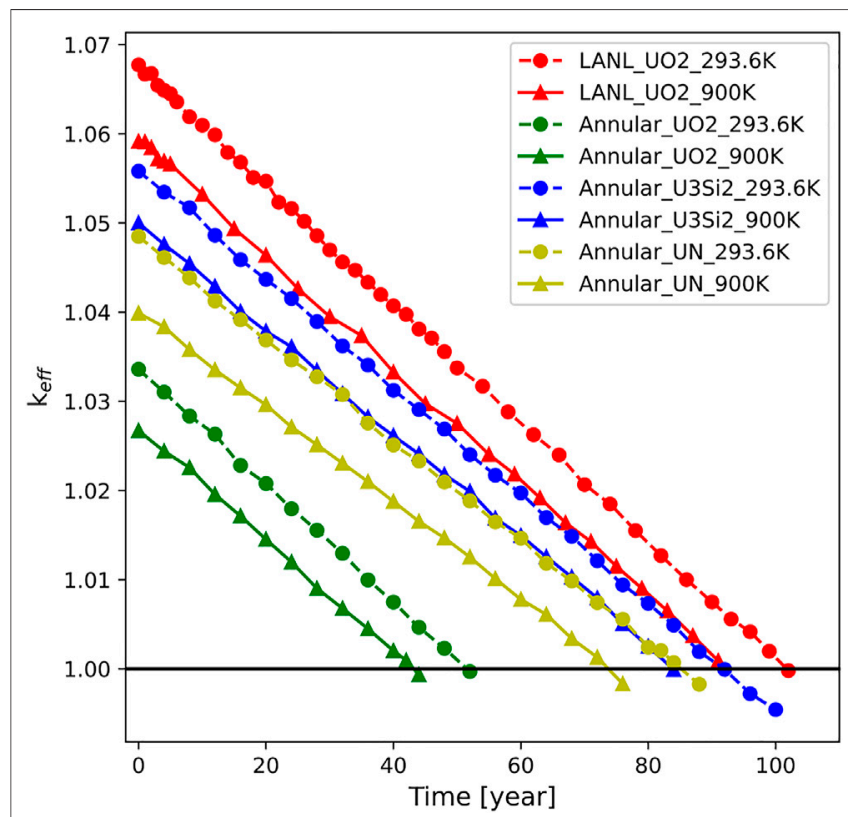

FIGURE 5 | Evolution of $k_{\text {eff }}$ for case A.

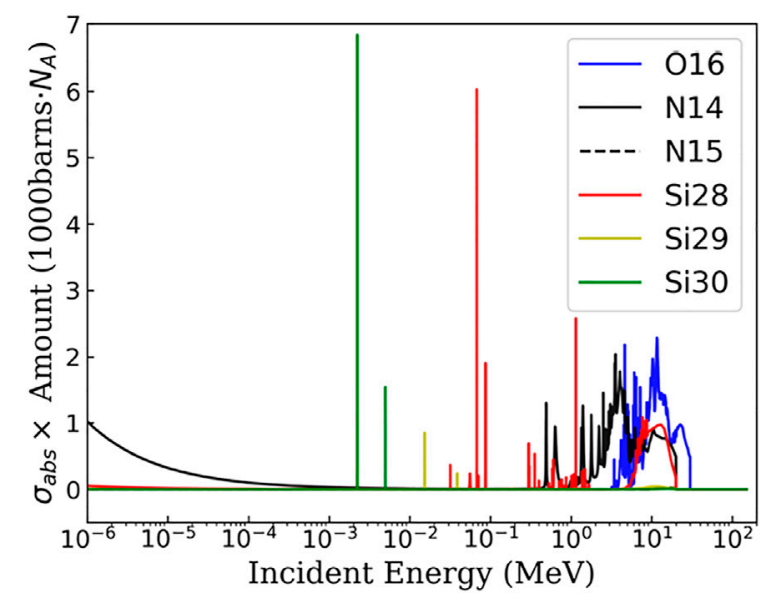

FIGURE $6 \mid \sigma_{\text {abs }} \times N$ with the change of the incident energy of neutron of $\mathrm{O} 16$ when $\mathrm{UO}_{2}$ is implemented in the annular fuel design, that of Si28, Si29, and $\mathrm{Si} 30$ when $\mathrm{U}_{3} \mathrm{Si}_{2}$ is implemented and that of $\mathrm{N} 14$ and $\mathrm{N} 15$ when $\mathrm{UN}$ is implemented. $\sigma_{\text {abs }}$ is the microscopic neutron absorption cross section and $N$ is the number of nuclides. $N_{A}=6.02 \times 10^{23}$. The data of cross section refer to ENDF/B-VII.1.

mentioned in Section Proposed Modification, the authors propose to replace the fuel pins with the fuel in a circular annular shape, which decreases the radial power gradient of the fuel pin. Besides the $\mathrm{UO}_{2}$ fuel used in the original LANL design, two ATF materials, $\mathrm{UN}$ and $\mathrm{U}_{3} \mathrm{Si}_{2}$, are involved.

As listed in Table 5, $\mathrm{k}_{\text {eff }}$ decreases when the control drums rotate towards the monolith where the fuel pins are located. The reactor becomes subcritical when absorbers are in the closest location to the core. This demonstrates that the critical position is situated between these two extreme rotation angles, which means the criticality can be reached by rotation of the control drums. As shown in Figure 5, the depletion chain of $900 \mathrm{~K}$ is always lower than that of $293.6 \mathrm{~K}$. $\mathrm{k}_{\text {eff }}$ decreases with the temperature increase.

We do not compare the results with Ref (Lee et al., 2019). because there are specific details, not only of materials composition but also of geometric information, undeclared in Ref. (Lee et al., 2019). In Lee et al.'s report, only the density of SS316 is declared as $8.03 \mathrm{~g} / \mathrm{cm}^{3}$ but not the composition of elements (Lee et al., 2019). The composition of SS316 used in the present work refers to Ref. (Sterbentz et al., 2017b), 68\% Fe, $14 \% \mathrm{Ni}$, and $18 \% \mathrm{Cr}$. Moreover, the $\mathrm{k}_{\text {eff }}$ decreases with Mo concentration in the SS316 composition, as shown in Table 6. But it still cannot reach the same scale as Ref. (Lee et al., 2019). Thus, this work brings into correspondence with Ref (Sterbentz et al., 2017b). for the composition of SS316.

The $\mathrm{k}_{\mathrm{eff}}$ simulated by OpenMC, as shown in Figure 5, shows a drop of $325 \mathrm{pcm}$ from the initial state to the fifth year under the temperature set to be $293.6 \mathrm{~K}$, and $254 \mathrm{pcm}$ under $900 \mathrm{~K}$ for case A. The depletion simulation presents consistency with Sterbentz et al.'s work, which showed that the $\mathrm{k}_{\mathrm{eff}}$ of LANL design dwindles about 300 pcm during the first 5 years (Sterbentz et al., 2017a). Moreover, the depletion calculation shows that the 5 years cycle length of LANL design can easily be achieved. In neutronic criteria, it can operate at the normal power for more than 90 years.

The depletion of the whole life of the core is calculated for each modified design and the original LANL design. Based on the $\mathrm{k}_{\mathrm{eff}}$ evolution in Figure 5, the maximum core lifetime with the standard power is reduced after replacing the original design with the annular fuel design. On the one hand, the fuel volume is reduced by $11.5 \%$ after the replacement, which decreases the $\mathrm{k}_{\mathrm{eff}}$. On the other hand, the reduced fuel volume is supplemented by SS316 that absorbs more neutrons. This explains why the green lines are lower than the red lines in Figure 5.

As for the annular fuel design, the amount of $\mathrm{U} 235$ in $\mathrm{UO}_{2}$ is less than that in $\mathrm{U}_{3} \mathrm{Si}_{2}$ and $\mathrm{UN}$, as shown in Figure 7. This is why the green line in Figure 5 is the lowest. In addition, the amount of $\mathrm{U} 235$ in $\mathrm{U}_{3} \mathrm{Si}_{2}$ is slightly less than that in the $\mathrm{UN}$, but the $\mathrm{k}_{\text {eff }}$ when $\mathrm{U}_{3} \mathrm{Si}_{2}$ is implemented is higher than that when $\mathrm{UN}$ is implemented, as shown in Figure 5. This is hard to explain. The only factor that can make influence is the appearance of $\mathrm{Si}$ 

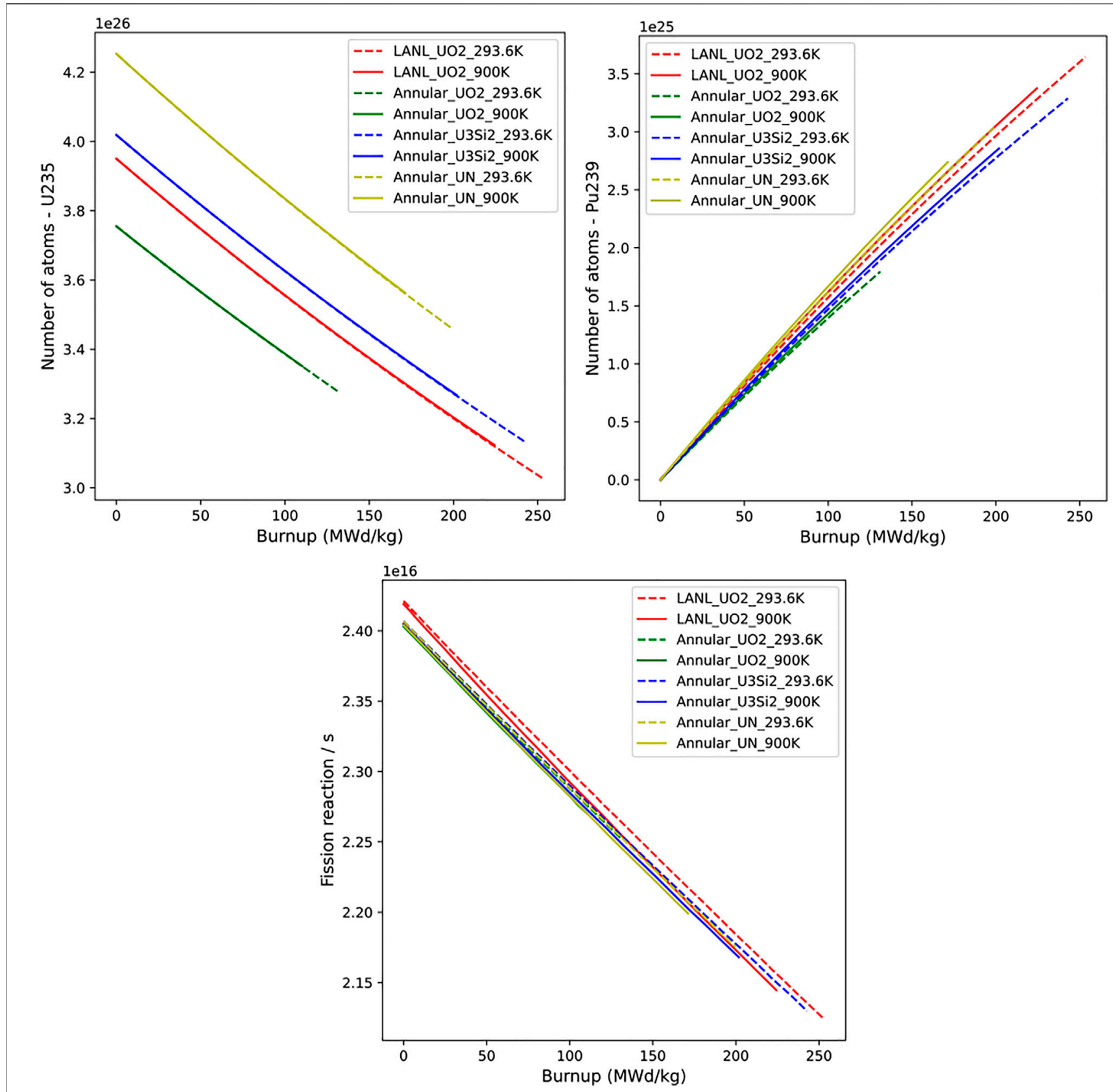

FIGURE 7 | Evolution of the number of U235, Pu239, and fission rate with depletion for the whole life on case A.

and $\mathrm{N}$ respectively in the two ATFs. As shown in Figure 6, even though the macroscopic neutron absorption cross section of N14 in $\mathrm{UN}$ is almost much larger than that of $\mathrm{Si}$ isotopes in $\mathrm{U}_{3} \mathrm{Si}_{2}$ in the fast energy region, there are still some resonance peaks of $\mathrm{Si}$ isotopes higher than that of N14.

The higher operating temperature also decreases the $\mathrm{k}_{\text {eff }}$ value in the whole cycle and reduces the cycle length. But it rarely influences the evolution of uranium amount, as shown in Figure 7, since the depletion is motivated by a fixed thermal power. Moreover, the increase in temperature reduces the fission rate of $\mathrm{U} 235$ and increases the production rate of $\mathrm{Pu} 239$.

\section{SUMMARY AND OUTLOOK}

In summary, a heat pipe design with annular fuel is proposed to enhance the LANL megawatt heat pipe design, and the neutronic properties are investigated.

Firstly, the effects of $\mathrm{BeO}$ and $\mathrm{Al}_{2} \mathrm{O}_{3}$ as the axial reflector are compared. This paper suggests a reduced amount of $\mathrm{BeO}$ in the bottom reflector to generate a more balanced axial power distribution.

Besides the $\mathrm{UO}_{2}$, the other two types of ATFs, i.e., UN and $\mathrm{U}_{3} \mathrm{Si}_{2}$, are studied in the present work. For both designs with 
different fuel materials, the criticality by the rotation of control drums is verified.

Moreover, the depletion calculation presents the evolution of $\mathrm{k}_{\mathrm{eff}}$, the total fission rate, and the amount of U235 and Pu239 in the fuel. The depletion with different temperatures is also investigated, which shows that $\mathrm{k}_{\text {eff }}$ decreases with increasing temperature. The amount of U235 seems to be rarely influenced by the operation temperature, while the increase of operation temperature increases the Pu239 amount.

For further investigation, the model established in this work can be coupled with the heat transfer model to achieve multiphysics coupling simulation. The temperature distribution of fuel, the accident of loss of fuel element, and that of loss of heat pipe can be investigated.

\section{DATA AVAILABILITY STATEMENT}

The original contributions presented in the study are included in the article/Supplementary Material, further inquiries can be directed to the corresponding author.

\section{REFERENCES}

Arai, Y., Suzuki, Y., Iwai, T., and Ohmichi, T. (1992). Dependence of the thermal Conductivity of (U, Pu) $\mathrm{N}$ on Porosity and Plutonium Content. J. Nucl. Mater. 195 (1-2), 37-43. doi:10.1016/0022-3115(92)90361-n

Brown, N. R., Todosow, M., and Cuadra, A. (2015). Screening of Advanced Cladding Materials and UN-U3Si5 Fuel. J. Nucl. Mater. 462, 26-42. doi:10. 1016/j.jnucmat.2015.03.016

Burkes, D. E., Casella, A. M., Casella, A. J., Buck, E. C., Pool, K. N., MacFarlan, P. J., et al. (2015). Thermal Properties of U-Mo Alloys Irradiated to Moderate Burnup and Power. J. Nucl. Mater. 464, 331-341. doi:10.1016/j.jnucmat. 2015.04.040

Bushman, A., Carpenter, D. M., Ellis, T. S., Gallagher, S. P., Hershcovitch, M. D., Hine, M. C., et al. (2004). The Martian Surface Reactor: An Advanced Nuclear Power Station for Manned Extraterrestrial Exploration. MIT-NSA-TR-003.

Chen, S. L., He, X. J., and Yuan, C. X. (2020). Recent Studies on Potential AccidentTolerant Fuel-Cladding Systems in Light Water Reactors. Nucl. Sci. Tech. 31 (3), 32. doi:10.1007/s41365-020-0741-9

Chen, S. L., and Yuan, C. X. (2017). Neutronic Analysis on Potential Accident Tolerant Fuel-Cladding Combination U3Si2-FeCrAl. Sci. Technology Nucl. Installations 2017, 3146985. doi:10.1155/2017/3146985

Chen, S., Ge, Y., Zhong, Y., and Yuan, C. (2020). Radial Distributions of Power and Fuel Temperature in Annular U3Si2 Fuel with FeCrAl Cladding. Ann. Nucl. Energ. 135, 106943. doi:10.1016/j.anucene.2019.106943

Chen, S., Yuan, C., and Guo, D. (2019). Radial Distributions of Power and Isotopic Concentrations in Candidate Accident Tolerant Fuel U3Si2 and UO2/U3Si2 Fuel Pins with FeCrAl Cladding. Ann. Nucl. Energ. 124, 460-471. doi:10.1016/j. anucene.2018.10.025

Chen, S., and Yuan, C. (2019). Minor Actinides Transmutation in Candidate Accident Tolerant Fuel-Claddings U3Si2-FeCrAl and U3Si2-SiC. Ann. Nucl. Energ. 127, 204-214. doi:10.1016/j.anucene.2018.12.003

El-Genk, M. S., and Tournier, J. M. (2004a). Conceptual Design of HP-STMCs Space Reactor Power System for 110 kWe. AIP Conf. Proc. 699 (1), 658-672. doi:10.1063/1.1649628

El-Genk, M. S., and Tournier, J. M. (2004b). Performance Analysis of Potassium Heat Pipes Radiator for HP-STMCs Space Reactor Power System. AIP Conf. Proc. 699 (1), 793-805.doi:10.1063/1.1649644

El-Genk, M. S., and Tournier, J.-M. P. (2004). "SAIRS" - Scalable Amtec Integrated Reactor Space Power System. Prog. Nucl. Energ. 45 (1), 25-69. doi:10.1016/j. pnucene.2004.08.002

\section{AUTHOR CONTRIBUTIONS}

$\mathrm{CY}, \mathrm{BC}, \mathrm{TW}, \mathrm{YW}$, and $\mathrm{ZZ}$ contributed to conception and design of the study. $\mathrm{BC}$, TW, and $\mathrm{YW}$ perform and verify the calculations. BC and CY wrote the first draft of the manuscript. All authors contributed to manuscript revision, read, and approved the submitted version.

\section{FUNDING}

This work has been supported by the National Key Research and Development Program of China under Grant No. 2018YFB1900405, the National Natural Science Foundation of China under Grant No. 11775316, the Tip-top Scientific and Technical Innovative Youth Talents of Guangdong special support program under Grant No. 2016TQ03N575, the International Sci \& Tech Cooperation Program of Guangdong Province No. 2019A050510022, Fundamental Major Sci \& Tech Special Project of Guangdong Province No. 2019B030302011, and the computational resources from SYSU and National Supercomputer Center in Guangzhou.

Hayes, S. L., Thomas, J. K., and Peddicord, K. L. (1990). Material Property Correlations for Uranium Mononitride: III. Transport Properties. J. Nucl. Mater. 173 (2-3), 289-299. doi:10.1016/0022-3115(90)90376-x

Hofman, G. L. (1986). Crystal Structure Stability and Fission Gas Swelling in Intermetallic Uranium Compounds. J. Nucl. Mater. 140 (3), 256-263. doi:10. 1016/0022-3115(86)90208-4

Houts, M. G., Poston, D. I., Berry, D. L., and Polansky, G. F. (1996). Near-term, Low-Cost Fission Power and Propulsion Systems for Space Applications. Huntsville, AL: Space Programs and Technologies Conference, 4464.

Houts, M. G., Poston, D. I., and Ranken, W. A. (1996). HPS: A Space Fission Power System Suitable for Near-Term, Low-Cost Lunar and Planetary Bases. Eng. Construction, Operations Space V 119, 973-983. doi:10.1061/40177(207)131

Lee, C., Jung, Y. S., and Cho, H. K. (2019). Micro Reactor Simulation Using the PROTEUS Suite in FY19. Argonne, IL: ANS/NSE-19/33. doi:10.2172/1571248

Levinsky, A., van Wyk, J. J., Arafat, Y., and Smith, M. C. (2018). Westinghouse eVinci Reactor for Off-Grid Markets. Transactions 119 (1), 931-934.

Mcclure, P. R., Poston, D. I., Dasari, V. R., and Reid, R. S. (2015). Design of Megawatt Power Level Heat Pipe Reactors. LA-UR- 15-28840.doi:10.2172/1226133

Muta, H., Kurosaki, K., Uno, M., and Yamanaka, S. (2008). Thermal and Mechanical Properties of Uranium Nitride Prepared by SPS Technique. J. Mater. Sci. 43, 6429-6434. doi:10.1007/s10853-008-2731-x

Poston, D. I. (2001). The Heatpipe-Operated Mars Exploration Reactor (HOMER). AIP Conf. Proc. 552 (1), 797-804.

Romano, P. K., Horelik, N. E., Herman, B. R., Nelson, A. G., Forget, B., and Smith, K. (2015). OpenMC: A State-Of-The-Art Monte Carlo Code for Research and Development. Ann. Nucl. Energ. 82, 90-97. doi:10.1016/j.anucene.2014.07.048

Ross, S. B., El-Genk, M. S., and Matthews, R. B. (1988). Thermal Conductivity Correlation for Uranium Nitride Fuel between 10 and 1923 K. J. Nucl. Mater. 151 (3), 318-326. doi:10.1016/0022-3115(88)90026-8

Solntceva, E. S., Taubin, M. L., Vybyvanets, V. I., Galyov, I. E., Baranov, V. G., Homyakov, O. V., et al. (2016). Thermal Conductivity of Perspective Fuel Based on Uranium Nitride. Ann. Nucl. Energ. 87, 799-802. doi:10.1016/j.anucene. 2014.08.011

Sterbentz, J. W., Werner, J. E., Hummel, A. J., Kennedy, J. C., O’Brien, R. C., Dion, A. M., et al. (2017). Preliminary Assessment of Two Alternative Core Design Concepts for the Special Purpose Reactor. Idaho Falls, ID: INL/EXT-17-43212. doi:10.2172/1413987

Sterbentz, J. W., Werner, J. E., McKellar, M. G., Hummel, A. J., Kennedy, J. C., Wright, R. N., et al. (2017). Special Purpose Nuclear Reactor (5 MW) for Reliable Power at Remote Sites Assessment Report. Idaho Falls, ID: INL/EXT-16-40741. doi:10.2172/1410224 
White, J. T., Nelson, A. T., Dunwoody, J. T., Byler, D. D., Safarik, D. J., and McClellan, K. J. (2015). Thermophysical Properties of U3Si2 to 1773 K. J. Nucl. Mater. 464, 275-280. doi:10.1016/j.jnucmat.2015. 04.031

Yan, B. H., Wang, C., and Li, L. G. (2020). The Technology of Micro Heat Pipe Cooled Reactor: A Review. Ann. Nucl. Energ. 135, 106948. doi:10.1016/j. anucene.2019.106948

Zeng, Z. T., Pan, Y. Y., Chen, X., Zhang, C. Y., Yin, C. Y., Gao, S. X., et al. (2021). Three-Dimensional Modeling of Thermal-Mechanical Behavior of Accident Tolerant Fuels. Front. Energ. Res. 9, 87. doi:10.3389/fenrg.2021. 636502
Conflict of Interest: The authors declare that the research was conducted in the absence of any commercial or financial relationships that could be construed as a potential conflict of interest.

Copyright $\odot 2021$ Cai, Chen, Wu, Wang, Zhang, Yuan, Zhang and Ge. This is an open-access article distributed under the terms of the Creative Commons Attribution License (CC BY). The use, distribution or reproduction in other forums is permitted, provided the original author(s) and the copyright owner(s) are credited and that the original publication in this journal is cited, in accordance with accepted academic practice. No use, distribution or reproduction is permitted which does not comply with these terms. 